\title{
Regional Differences in Adult Body Height in Kosovo
}

\author{
Bojan Masanovic ${ }^{1}$, Tonci Bavcevic ${ }^{2}$, Ivan Prskalo ${ }^{3}$
}

Affiliations: 'University of Montenegro, Faculty for Sport and Physical Education, Niksic, Montenegro, ${ }^{2}$ University of Split, Faculty of Kinesiology, Split, Croatia, ${ }^{3}$ University of Zagreb, Faculty of Teacher Education, Zagreb, Croatia

Correspondence: B. Masanovic, University of Montenegro, Faculty for Sport and Physical Education, Narodne omladine bb, 81400 Niksic, Montenegro. E-mail: bojanma@ucg.ac.me

ABSTRACT This study aimed to test average body heights in both the male and females of Kosovo, as well as the differences in heights of both sexes in relation to the Kosovo administrative regions. A total of 1623 subjects participated in the research: 830 boys and 793 girls all attending their final year of secondary school. The anthropometric measurements were taken for subjects of both sexes from five different administrative regions of Kosovo. The measurements of body heights were taken by trained measurers in conformity with the ISAK protocol. Means and standard deviations were calculated for ages and body heights, as were frequencies for the calculation of the density of very short and very tall subjects. The results indicated that the average height of the male population of Kosovo was $179.52 \pm 5.96$ centimetres and of the female population $165.72 \pm 4.93$ centimetres. These results classify both the male and female populations of Kosovo among the tallest in the world. Regarding the regional differences, some variations have been observed, and the differences in body heights among specific regions clearly confirm the assumption that the population living in the Dinaric Alps is taller in relation to the rest of the population, while the specific average height of the central region, where the capital city is located, reflects the expected situation conditioned by continuous migrations from all other parts of Kosovo, as well as the fact that there is a growing secular trend towards the territory of the capital city, due to better economic and living conditions.

KEY WORDS Standing Height; Stature; Local Differences; Kosovo

@MJSSMontenegro

ADULT HUMAN HEIGHT IN KOSOVO

http://mjssm.me/?sekcija=article\&artid=175

\section{Introduction}

Researchers from Europe, the USA, and Japan were interested in trends in changes of body height in males, and the research was later extended to other regions throughout the world; the interest in the estimation of body height in males has a rather clear and long tradition, while the interest in body height in females has been recent (Popovic, 2018). Some were simply curious, and the others had practical reasons for research. In most societies, being tall was in a high correlation with positive attitudes as far as the acceptance of a group is concerned, above all because being taller has also meant being stronger, which was a significant factor in times of the turbulent history of development of humankind, contributing to survival (Popovic, 2018); these attitudes possibly remain on the territory of the region of the Western Balkans. Furthermore, being tall was also in a high correlation with the perception of being attractive and acceptable for the majority of conservative societies, especially in male populations, as the tendency was to compare a person's height in relation to members from his society and to praise him or her for being taller, implying more attractive, stronger, better, or similar.

Contemporary studies include increasing results on the average body height of modern nations; one of the most significant ones has been the research carried out by the NCD Risk Factor Collaboration (2016), particularly due to its sample, which included 1472 populations, 200 countries, and 18.6 million participants. The study showed results of the average height in adult males and females throughout the world in the $20^{\text {th }}$ century. However, this study failed to include data on the average height of the population of Kosovo, a country 
not included in any study, representing a significant fact for the present research as it can be considered as an addition to the above-mentioned study.

Furthermore, unlike the majority of European countries and those from the region of the Western Balkans, on the territory of Kosovo, the data on the average body height has never been gathered, so every initiative regarding research in this area is significant for both kinesiological anthropology and anthropology in general. The body height of the population of Kosovo was analysed in the studies that investigated the relation of body height and the length of the foot (Popovic, Arifi, \& Bjelica, 2017), as well as body height and arm span in Kosovo (Arifi et al., 2017), which can be used for determining the average height of Kosovans. However, a detailed analyses of the average height of the entire population, or even per administrative region has never been implemented before, which gives a special significance to this research, mostly due to the fact that the population of Kosovo, even though ethnic Albanians, show significantly higher values (almost $5 \mathrm{~cm}$ ) of body height in comparison to their neighbouring Albanians (personal communication, J. Jarani). Especially since one part of Kosovo lies in the area of a mountain range known as the Dinaric Alps, it is essential to determine if the type of the terrain is the reason for this difference in the average height between the Kosovans and Albanians, or to determine if there was perhaps another reason, as the aim of this study is to analyse the average values of the body height in administrative regions of Kosovo.

It is interesting to start the analyses with the fact that the borders of Kosovo are mountain ranges that are surrounding the middle part of the country, situated on a lower sea level, and consisting of plains, hills and hillocks. In addition to this low-lying part, it is necessary to point out that a bigger part, gravitating towards the southern border of Kosovo that is not a part of the Dinaric Alps, is the area of the Sharr Mountains (Alb.: Sharr). Furthermore, from the most eastern part of the Sharr Mountains towards the north, there is a mountain range known as the Skopska Crna Gora (Alb.: Karadak). Moreover, towards the northern part of Kosovo, the mountains do not reach even a half of the height as those from the southern part up to the slopes of Kopaonik ranging from central Serbia. Also, at the western part of Kosovo, from Montenegro to Albania, there is another mountain range known as the Prokletije or the Albanian Alps (Alb.: Bjeshket e Nemura) that are a geological extension of the Dinaric Alps (Figure 1).

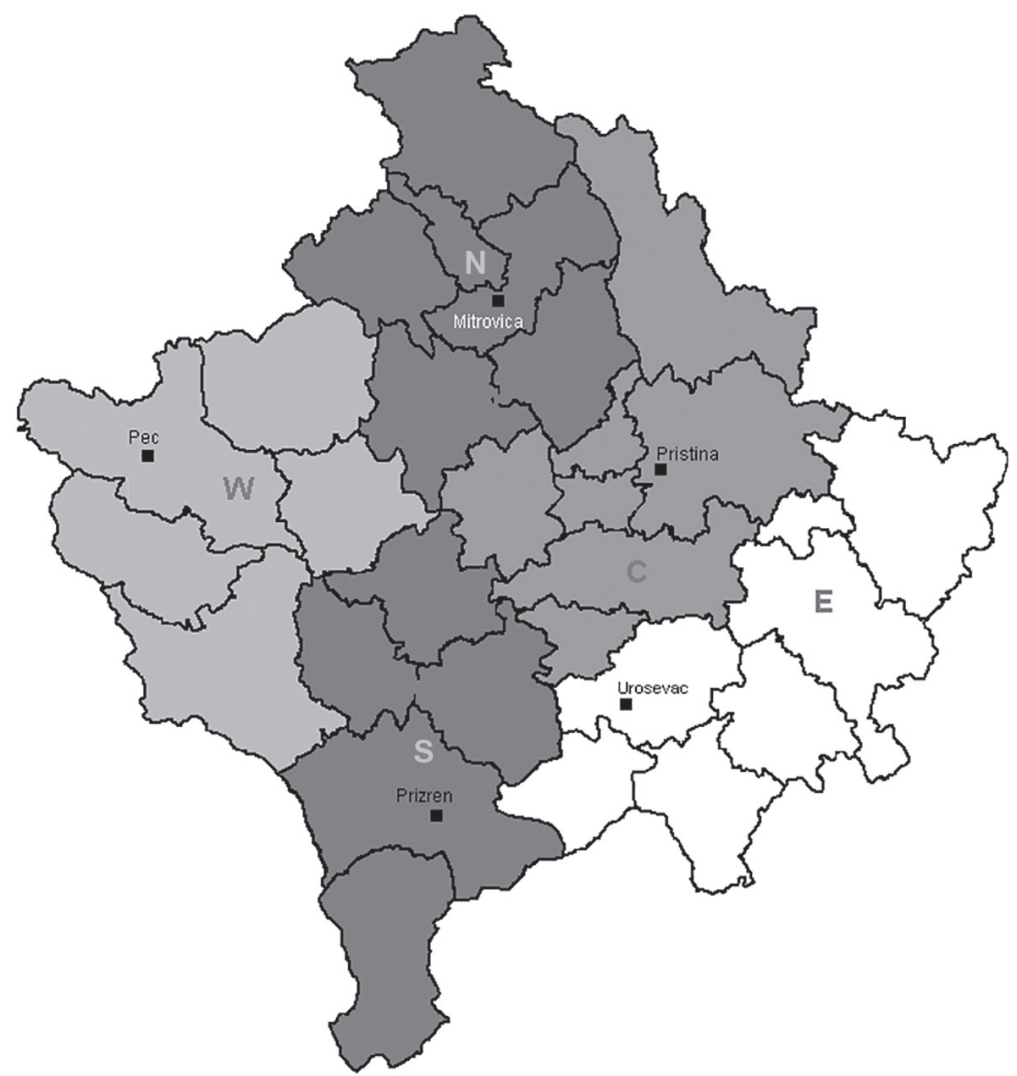

FIGURE 1 Administrative regions of Kosovo (Source: KFOR_Structur.2006, 2006)

It is important to introduce the terrain of Kosovo in order to make a clear division of the area between the mountain range of the Dinaric Alps and the other areas, especially due to a clear assumption that people living in the area of the Dinaric Alps are characterized by above average body height (Coon, 1939; Coon, 1970, Pineau, Delamarche, \& Bozinovic, 2005). The best example is Kosovo, which is inhabited by one ethnic group in the Dinaric Alps slopes and in other mountain ranges, which makes it challenging for further analyses to obtain an answer to a decades-old question regarding whether the tallest people in the world live there. Therefore, the results of this research would provide clear knowledge on the existence of differences in body 
height regarding the administrative regions of Kosovo, and confirm whether the tallest people live in the area of the Dinaric Alps (Pineau et al., 2005). In contrast, it would be expected that the population is on average somewhat shorter in the central part of Kosovo, outside the range of the Dinaric Alps. Furthermore, the capital city of Pristina is a place where people from all the regions meet after decades of migration due to better living conditions; therefore, it cannot be taken into consideration as a factor for any fundamental analyses, so it will only be analysed descriptively.

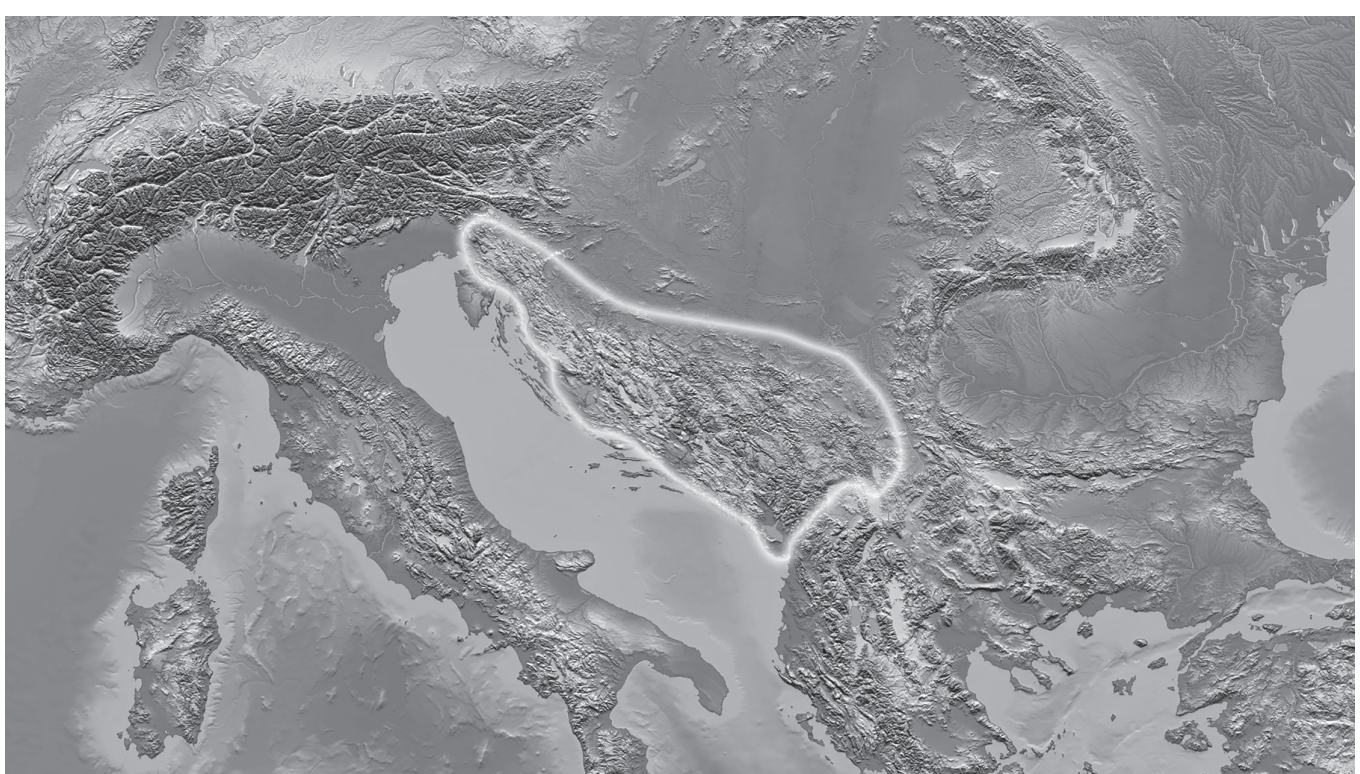

FIGURE 2 Borders of Dinaric Alps mountain range (Source: Zoom into Dinaric Alps mountain range, 2017)

Learning the average values of body height is not only crucial for a potential "test of strength" among the subjects living in certain municipalities and regions of Kosovo, but also for experts in the fields of medicine and public health as they can aid in the estimation of current nutritional status and obesity (Popovic, Bjelica, Tanase, \& Milasinovic, 2015), as well as for sports experts who can benefit from this information for early talent identification and orientation towards a sport that best suits the morphological characteristics of identified talented people (Grgantov et al., 2017; Masanovic, Milosevic, \& Corluka, 2018; Stoop, Hohenauer, Rucker, \& Clijsen, 2018). New research indicates that body height is connected to longevity and that tall mothers have less risk of unfavourable pregnancy outcomes. In addition, taller men and women have fewer health issues, such as cardiovascular and respiratory diseases, but they have a higher risk of some types of carcinoma (Quanjer et al., 2014; NCD Risk Factor Collaboration, 2016).

Therefore, this research has a multidisciplinary character, as it can be useful both to scholars from several fundamental and applied scientific fields, and applied in practice on the general population. Considering the lack of research in the area of Kosovo regarding body height, the authors of this study have conducted analyses on a sample that could represent the population of Kosovo on the representative level, analysing regional geographical differences, and determining the average values of body height according to the administrative region. Consequently, the basic aim of this study was to provide detailed analyses of regional geographical differences regarding the adult body height of both sexes and to obtain clear conclusions regarding the question of whether the population living in the Dinaric Alps is significantly taller than the population from the other mountain ranges or low-lying areas. It also aimed to provide the public with a rich database on the body height of males and females from all regions of Kosovo.

\section{Methods}

This study included a sample of 1623 final year students from five high schools from the administrative regions of Kosovo (northern, southern, eastern, western and central regions), divided into two subsamples: 830 male students $(18.25 \pm 0.45)$ and 793 female students $(18.24 \pm 0.43)$. This particular sample was selected because growth and development should be completed at this age. It is widely known that in this period there is no significant loss in body height due to different physiological reasons or external influences, which is the case for the older generations. In addition, it is important to emphasize that criteria for the selection of subjects for the sample were not having any physical deformity that might impact body height and having permanent residence on the territory of Kosovo.

The protocol of the International Society for the Advancement of Kinanthropometry (ISAK) was employed in ten secondary schools from Kosovo, including the municipalities of Decan, Ferizaj, Gjakova, Gjilan, Istog, Junik, Mitrovica, Peja, Pristina, and Prizren (Marfell-Jones, Olds, Stew, \& Carter 2006), and the body height measurements were taken by trained measurers. The age of the study subjects was determined from the date of taking the measurement and their reported date of birth. 
The average body height was calculated using the Statistical Package for the Social Sciences SPSS 23.0. Means, standard deviation, and the range of minimum and maximum values obtained from the measurements of body height are shown for both males and females from all five administrative regions of Kosovo, and for ten respective municipalities. The analyses also included the percentage of short (170 and 160 centimetres and lower) and tall people (190 and 200 centimetres and above).

\section{Results}

Analysis of the average body height of male subjects is shown in Table 1. The average body height of the overall sample of male subjects was $179.52 \pm 5.96$ centimetres, while the tallest subjects live in the central region of Kosovo $(180.62 \pm 5.88 \mathrm{~cm})$, the medium ones in the northern region $(180.29 \pm 5.72 \mathrm{~cm})$, shorter ones in the western region $(179 . \pm 5.88 \mathrm{~cm})$, those shorter than them in the southern region $(179.15 \pm 5.56 \mathrm{~cm})$, and finally the shortest ones live in the eastern region $(177.68 \pm 6.65 \mathrm{~cm})$ of Kosovo.

TABLE 1 Descriptive statistics among male subjects

\begin{tabular}{ccccccc} 
Municipality/Region & \multirow{2}{*}{$\mathbf{N}$} & \multicolumn{3}{c}{ Age } & \multicolumn{3}{c}{ Body height } \\
\cline { 3 - 7 } & & Mean & SD & Mean & SD & Range \\
\hline Deçan & 85 & 18.14 & 0.35 & 179.66 & 6.30 & $166.8-196.4$ \\
Ferizaj & 95 & 18.15 & 0.36 & 179.84 & 5.28 & $169.2-193.8$ \\
Gjakovë & 61 & 18.33 & 0.47 & 180.49 & 6.40 & $168.7-196.0$ \\
Gjilan & 90 & 18.26 & 0.24 & 177.68 & 6.65 & $161.4-191.1$ \\
Istog & 56 & 18.29 & 0.46 & 180.15 & 6.37 & $163.5-195.4$ \\
Junik & 45 & 18.24 & 0.48 & 177.75 & 5.37 & $167.6-188.2$ \\
Mitrovicë & 87 & 18.25 & 0.46 & 180.29 & 5.72 & $167.9-197.3$ \\
Pejë & 91 & 18.24 & 0.43 & 179.95 & 5.39 & $164.2-193.0$ \\
Prishtinë & 100 & 18.26 & 0.44 & 180.62 & 5.88 & $170.3-198.8$ \\
Prizren & 120 & 18.40 & 0.57 & 178.71 & 5.73 & $164.6-192.3$ \\
\hline Northern Region & 87 & 18.25 & 0.46 & 180.29 & 5.72 & $167.9-197.3$ \\
Western Region & 232 & 18.26 & 0.46 & 179.89 & 5.95 & $163.5-196.4$ \\
Central Region & 100 & 18.26 & 0.44 & 180.62 & 5.88 & $170.3-198.8$ \\
Eastern Region & 90 & 18.26 & 0.24 & 177.68 & 6.65 & $161.4-191.1$ \\
Southern Region & 215 & 18.29 & 0.49 & 179.15 & 5.56 & $164.6-193.8$ \\
\hline Total & 830 & 18.25 & 0.45 & 179.52 & 5.96 & $161.4-198.8$ \\
\hline
\end{tabular}

Analysis of the average body heights of female subjects is shown in Table 2. The mean of body height for the overall sample of female subjects is $165.72 \pm 4.93$ centimetres, while the tallest female subjects live in the central region of Kosovo $(166.77 \pm 4.72 \mathrm{~cm})$, the medium ones live in the western region $(166.33 \pm 5.36 \mathrm{~cm})$, shorter ones in the northern region $(165.36 \pm 4.56 \mathrm{~cm})$, those shorter than them in the southern region $(165.29 \pm 4.60$ $\mathrm{cm})$, and the shortest ones live in the eastern region $(164.10 \pm 4.61 \mathrm{~cm})$ of Kosovo.

\begin{tabular}{ccccccc}
\hline \multirow{2}{*}{ TABLE 2 Descriptive statistics among female subjects } \\
Municipality/Region & $\mathbf{N}$ & \multicolumn{2}{c}{ Age } & \multicolumn{3}{c}{ Body Height } \\
\cline { 3 - 7 } & & Mean & SD & Mean & SD & Range \\
\hline Deçan & 68 & 18.29 & 0.46 & 166.39 & 5.60 & $157.8-181.8$ \\
Ferizaj & 79 & 18.13 & 0.33 & 165.22 & 4.81 & $158.2-177.5$ \\
Gjakovë & 63 & 18.17 & 0.38 & 165.78 & 3.96 & $159.3-177.9$ \\
Gjilan & 100 & 18.17 & 0.38 & 164.10 & 4.61 & $153.3-173.4$ \\
Istog & 68 & 18.29 & 0.52 & 166.42 & 5.38 & $157.0-178.7$ \\
Junik & 38 & 18.32 & 0.47 & 166.59 & 6.25 & $157.2-181.3$ \\
Mitrovicë & 90 & 18.29 & 0.46 & 165.36 & 4.56 & $158.7-182.0$ \\
Pejë & 89 & 18.22 & 0.42 & 166.22 & 5.23 & $153.3-180.7$ \\
Prishtinë & 93 & 18.15 & 0.36 & 166.77 & 4.72 & $157.3-185.0$ \\
Prizren & 105 & 18.36 & 0.50 & 165.34 & 4.46 & $158.0-184.0$ \\
\hline Northern Region & 90 & 18.29 & 0.46 & 165.36 & 4.56 & $158.7-182.0$ \\
Western Region & 225 & 18.21 & 0.41 & 166.33 & 5.36 & $153.5-181.8$ \\
Central Region & 93 & 18.15 & 0.36 & 166.77 & 4.72 & $157.3-185.0$ \\
Eastern Region & 100 & 18.17 & 0.38 & 164.10 & 4.61 & $153.3-173.4$ \\
Southern Region & 184 & 18.26 & 0.45 & 165.29 & 4.60 & $158.0-184.0$ \\
\hline Total & 793 & 18.24 & 0.43 & 165.72 & 4.93 & $163.3-185.0$ \\
\hline
\end{tabular}




\section{Discussion}

This research contributes to an update on adult human heights among subjects of both sexes in Kosovo, both globally and partially per administrative regions. The contribution is evident due to the lack of relevant data from previous research in this area, and the fact that a global study carried out by NCD Risk Factor Collaboration (2016) failed to include in its analyses the trend of changes in body height of the population of Kosovo. Consequently, the aforementioned study excluded Kosovans as well as a few other countries from this research, which analysed 1472 populations in 200 countries and comprised more than 18.6 million participants.

The results of this research study classify both males and females from Kosovo in a group of tall, but not the tallest nations in the world. The Kosovo males, with an average height of 179.52 centimetres, are not classified among the ten tallest nations in the world, but they are quite close to making the first ten due to a positive influence of the secular trend. If we classify the population living in the Dinaric Alps, the Kosovan males would be shorter than the 183.8 centimetres of the Bosnian and Herzegovinian male population (Gardasevic, Rasidagic, Krivokapic, Corluka, \& Bjelica, 2017), the 183.36 centimetres of the Montenegrin male population (Popovic, 2017), the 182 centimetres of Serbian males (Popovic et al., 2013), the 180.5 centimetres of Croatian males (Juresa et al., 2012), or the 180.3 centimetres of Slovenian males (Starc \& Strel, 2011). However, if we compare the average body height of males from Kosovo with the body heights of other nations, first of all with those in the region and wider, we observe interesting facts such as that the Kosovo male population is taller than the 178.1 centimetres of the Macedonian male population (Popovic, Bjelica, Georgijev, Krivokapic, \& Milasinovic 2016), the 174 centimetres of Albanian males (Grasgrube, Cacek, Kalina, \& Seberaet, 2014), the 178.8 centimetres of Austrian males (Hatton \& Bray, 2010), the 177 centimetres of French males (Heroin, 2003), or the 178.1 centimetres of Greek males (Papadimitriou et al., 2008).

In contrast, the Kosovo female population, whose average height is 165.72 centimetres, is also one of the tallest nations in the world. If we classify the population living in the Dinaric Alps, the Kosovo female population is shorter than the 171.8 centimetres of the Bosnian and Herzegovinian females (Popovic et al., 2015), the 168.3 centimetres of the Montenegrin (Bjelica et al., 2012), the 167.4 centimetres of the Slovenians (Starc \& Strel, 2011), the 166.8 centimetres of the Serbians (Popovic et al., 2013), or the 166.5 centimetres of the Croats (Juresa et al., 2012). Also, as in the case of the male populations, if we compare the average height of the Kosovo females with the average height of the other nations in the region and beyond, the results are intriguing. The female Kosovo population is taller than the 164.58 centimetres of the Macedonian females (Popovic et al., 2016), the 161.08 centimetres of Albanian females (Grasgrube et al., 2014), the 164.6 centimetres of French females (Herpin, 2003), the 162.5 centimetres of Italian females (Grasgrube et al., 2014), the 165.1 centimetres of Polish females (Kulaga et al., 2011), or the 161.9 of Turkish females (Iseri \& Arslan, 2009). Data on both male and female populations of Kosovo clearly confirm its specific heights and the importance of answering the question related to the extremely high values of average body heights of populations living in the area of the Dinaric Alps, as well as the differences among the populations belonging to the same ethnic group living in Kosovo and Albania.

It is the conclusion of the authors of the current research that the average body height of both gender-based groups from Kosovo in this study does not represent the maximum potential that might be reached by the population of Kosovo. Specifically, subjects from this study were boys and girls born in 1998. This year is intriguing as many inhabitants from the neighbouring countries might remember, but to remind those living in other parts of Europe or the world, at the end of the $20^{\text {th }}$ century the children born in 1998 were growing up in a period of war and great crises which led to poor socio-economic conditions, which were reflected in the quality of life, and consequently also human body height (Popovic, 2018). Based on this, it can be concluded that the population of Kosovo still has not reached its maximum genetic potential, and the secular trend has yet to be completed. In addition, it is realistic to expect that the coming generations will reach a height that will place them among the world's tallest nations. Thus, the new generations will face a whole range of questions regarding the value of body height, all earlier discussed in detail.

The average body height of an overall population is interesting when comparing nations. However, this study carries another, rather more interesting analysis that indicates differences among geographic areas of the Dinaric Alps and other mountain ranges where, as a rule, the tallest people in the world live.

The population of the central region is the tallest $(180.62 \mathrm{~cm})$, which was unexpected but logical. The authors of this study did not expect to find the tallest subjects in the central region, as it is not situated in the Dinaric Alps, which is most probably due to migrations from other parts of Kosovo towards the capital city in recent decades, since the capital city offered better economic and living conditions. Still, more attention should be paid to better living conditions than to migrations, as there is no available data. However, it can be assumed that people migrated from both Dinaric and other regions, so these results are explained by the secular trend in the central region where Pristina, the capital city of Kosovo, is situated. Therefore, the capital city should be omitted from future analysis due to the previously mentioned facts, which are interfering with the hypotheses of this study. On the second, third and fourth places are, from the tallest to the shortest people, the northern $(180.29 \mathrm{~cm})$, western $(179.89 \mathrm{~cm})$ and southern region $(179.15 \mathrm{~cm})$, all positioned in the Dinaric Alps, which conforms with the assumptions made by the authors. This represents evidence that the inhabitants from the Dinaric Alps belong to an extremely tall population as far as the average height is concerned. However, it 
is also noteworthy to point out that the eastern parts of the Northern and Southern Region are not entirely positioned in the Dinaric Alps, so a more detailed image of the situation might be obtained by implementing a national survey of the entire population of Kosovo, and not only on a representative sample as in this study. Nevertheless, the rest of the region should also be included. This is the eastern region where the shortest males in Kosovo $(177.68 \mathrm{~cm})$ live, and it is not near the Dinaric Alps whatsoever.

In contrast, regarding the female population of Kosovo, the results are quite similar. The highest values of the average body height were determined for female subjects from the Central Region $(166.77 \mathrm{~cm})$, while on the second, third and fourth places are the western $(166.33 \mathrm{~cm})$, northern $(165.36 \mathrm{~cm})$ and southern region, $(165.29 \mathrm{~cm})$, all positioned in the Dinaric Alps, while the shortest female subjects live in the eastern region $(164.10 \mathrm{~cm})$. Results obtained for the female population indicate similar conclusions regarding the hypotheses as in the case of the male population.

Even though not all municipalities of Kosovo were available, it is worth to analysing the available ones as an introduction to a new and more detailed study, which might include the overall population. As far as the average body heights per municipalities are concerned, the variation is more expressed in male subjects (2.94 $\mathrm{cm}$ ) in relation to female subjects for which the range from the minimum to maximum value is slightly lower $(2.67 \mathrm{~cm})$. Accordingly, the average body height ranges from 177.68 centimetres in the municipality of Gjilan to 180.62 centimetres in the municipality of Pristina for male subjects, and from 164.1 centimetres to 166.77 centimetres in the respective municipalities for female subjects. Estimation of the average body height according to municipality makes sense only if it could provide a clearer idea for analysing parts of the northern and eastern region as they are not situated in the Dinaric Alps entirely. The available analysis of the average body height values per municipalities is shown in detail in Table 1 for male subjects and in Table 2 for female subjects. In this part of the discussion the authors had no possibility of carrying out a more specific analysis of the narrow local areas, firstly due to the fact they only had limited data available. However, the authors included the available data, even though they knew the limitations, as they considered it could be beneficial for future research and consequently lead to collecting data that might be useful for drawing eagerly expected conclusions on determining carefully the value of the average body height in the population from the municipalities from the northern and southern region, situated in the Dinaric Alps, as well as in the population from the municipalities of the regions not situated in the Dinaric Alps.

Besides the average body height analysed on the overall sample, and on the subsamples of subjects per regions, it is interesting to analyse the density of very tall and very short subjects, particularly because a high value of very tall subjects is characteristic of the population of Kosovo's neighbours. The aim was to summarize the gathered information, which is quite important for the process of talent identification in certain sports disciplines. The density of very tall male subjects is not characteristic of the population of Kosovo since not even one of the subjects was above 200 centimetres, and only $5 \%$ of subjects were above 190 centimetres. Accordingly, the density of very tall male subjects in Kosovo has still not reached the results determined by Pineau et al. (2005) for the Dinaric Alps population, which is reflected in 28\% of subjects taller than 190 centimetres. Still, it can be noticed that there are significantly more tall subjects in Kosovo (190 centimetres and above) than in France where the percentage is $1 \%$ (Pineau et al., 2005). It is interesting to point out that there were no subjects shorter than 160 centimetres, while there was only a small number of those shorter than 170 centimetres at the level of the entire nation (4.6\%). The greatest percentage of extremely short subjects was

\begin{tabular}{|c|c|c|c|c|}
\hline Municipality/Region & $\begin{array}{c}\text { Below } \\
160 \mathrm{~cm}(\%)\end{array}$ & $\begin{array}{c}\text { Below } \\
170 \mathrm{~cm}(\%)\end{array}$ & $\begin{array}{c}\text { Above } \\
190 \mathrm{~cm}(\%)\end{array}$ & $\begin{array}{c}\text { Above } \\
200 \mathrm{~cm}(\%)\end{array}$ \\
\hline Deçan & 0 & 8.2 & 8.4 & 0 \\
\hline Ferizaj & 0 & 2.1 & 3.3 & 0 \\
\hline Gjakovë & 0 & 3.3 & 8.0 & 0 \\
\hline Gjilan & 0 & 12.2 & 4.4 & 0 \\
\hline Istog & 0 & 3.6 & 5.4 & 0 \\
\hline Junik & 0 & 6.6 & 0 & 0 \\
\hline Mitrovicë & 0 & 1.1 & 4.6 & 0 \\
\hline Pejë & 0 & 2.2 & 5.5 & 0 \\
\hline Prishtinë & 0 & 0 & 8.0 & 0 \\
\hline Prizren & 0 & 6.7 & 2.5 & 0 \\
\hline Northern Region & 0 & 1.1 & 4.6 & 0 \\
\hline Western Region & 0 & 3.9 & 6.5 & 0 \\
\hline Central Region & 0 & 0 & 8.0 & 0 \\
\hline Eastern Region & 0 & 12.2 & 4.4 & 0 \\
\hline Southern Region & 0 & 11.4 & 2.8 & 0 \\
\hline Total & 0 & 4.6 & 5.0 & 0 \\
\hline
\end{tabular}


found in the municipality of Gjilana (6.7\%), which is situated in the eastern part of Kosovo, an area furthest from the Dinaric Alps. A significant percentage of extremely short subjects was also found in the municipality of Prizren (6.7\%), also situated in the east, which confirms the hypothesis on differences in body composition of the inhabitants living in the Dinaric Alps, and those beside them.

In contrast, the municipality of Decani that is situated in the Dinaric Alps is rather interesting for observation since in this area it has been determined that $8.2 \%$ of subjects have an average body height of 170 centimetres or below, which is unexpected since a density of subjects measured 190 centimetres and taller (8.4\%) has been determined in the same municipality. In accordance with this fact, the average height of male subjects from the previously mentioned municipality exceeds the average values of the entire Kosovo population $(179.66 \mathrm{~cm})$, but this fact should be taken with caution since detailed analyses of the subsamples indicate certain unexpected variations, preventing us from claiming that the population of the Dinaric Alps is unconditionally the world's tallest. Detailed analysis of the density of extremely tall and extremely short subjects is shown in Table 3 .

As in the case of the male population, the density of the female population is not characteristic of the Kosovo female population, considering there was not even one female subject taller than 190 centimetres, and only $1.2 \%$ of female subjects were taller than 180 centimetres. It is also noteworthy that a percentage of extremely tall female subjects were established in two municipalities from the area of the Dinaric Alps in the west of Kosovo. These are the municipalities of Junik with $5.3 \%$ and Decani with $2.9 \%$ of female subjects with 180 centimetres or more. In the municipalities of Ferizaj and Gjilan, which are positioned in the eastern part of Kosovo, not even one female subject was taller than 180 centimetres. This was also the case of the municipalities of Gjakova and Istog, which is surprising as they gravitate towards the area that is considered to have an impact of high values of the density of tall female subjects. However, a detailed analysis is given in Table 4, and it can significantly contribute to experts from the area of sport for providing realistic expectations in the process of talent identification among girls.

\begin{tabular}{|c|c|c|c|c|}
\hline Municipality/Region & $\begin{array}{c}\text { Below } \\
150 \mathrm{~cm}(\%)\end{array}$ & $\begin{array}{c}\text { Below } \\
160 \mathrm{~cm}(\%)\end{array}$ & $\begin{array}{c}\text { Above } \\
180 \mathrm{~cm}(\%)\end{array}$ & $\begin{array}{c}\text { Above } \\
190 \mathrm{~cm}(\%)\end{array}$ \\
\hline Deçan & 0 & 7.4 & 2.9 & 0 \\
\hline Ferizaj & 0 & 15.2 & 0 & 0 \\
\hline Gjakovë & 0 & 1.6 & 0 & 0 \\
\hline Gjilan & 0 & 25.0 & 0 & 0 \\
\hline Istog & 0 & 11.8 & 0 & 0 \\
\hline Junik & 0 & 18.4 & 5.3 & 0 \\
\hline Mitrovicë & 0 & 8.9 & 1.1 & 0 \\
\hline Pejë & 0 & 10.1 & 1.1 & 0 \\
\hline Prishtinë & 0 & 3.2 & 1.1 & 0 \\
\hline Prizren & 0 & 8.6 & 1.0 & 0 \\
\hline Northern Region & 0 & 8.9 & 1.1 & 0 \\
\hline Western Region & 0 & 12.0 & 1.3 & 0 \\
\hline Central Region & 0 & 3.2 & 1.1 & 0 \\
\hline Eastern Region & 0 & 25.0 & 0 & 0 \\
\hline Southern Region & 0 & 11.4 & 0.5 & 0 \\
\hline Total & 0 & 11.0 & 1.2 & 0 \\
\hline
\end{tabular}

Finally, it is necessary to emphasize that the ongoing trend indicating that the populations living in the area of the Dinaric Alps are the tallest in the world is still active. However, these speculations should be avoided, giving future studies solid foundations for global research to have these conclusions, which seem possible in light of this study. Therefore, it is recommended that further research should be first oriented towards implementation of national surveys in countries from the area of the Dinaric Alps, especially because such research might provide detailed analyses if later needed. In addition, this is the main limitation of this study, as the authors had no possibility of determining differences on the micro level, which needed this as the sample of subjects was constructed as a representative sample of the administrative regions of Kosovo. Altogether, this study provided a clear and quality contribution to contemporary anthropology, representing a quality addition to the previous global studies, which failed to include the population of Kosovo in their research.

\section{REFERENCES}

Arifi, F., Bjelica, D., Sermaxhaj, S., Gardasevic, J., Kezunovic, M., \& Popovic, S. (2017). Stature and its Estimation Utilizing Arm Span Measurements in Kosovan Adults: National Survey. International Journal of Morphology, 35(3), 1161-1167. doi: 10.4067/S0717-95022017000401316

Bjelica, D., Popovic, S., Kezunovic, M., Petkovic, J., Jurak, G., \& Grasgruber, P. (2012). Body Height and Its 
Estimation Utilizing Arm Span Measurements in Montenegrin Adults. Anthropological Notebooks, 18(2), 69-83.

Coon, C. (1939). The races of Europe. New York: Macmillan Publishers.

Coon, C. (1970). The mountains of giants. Papers of the Peabody Museum of American Anthropology. New York: Kraus Reprint Co.

Gardasevic, J., Rasidagic, F., Krivokapic, D., Corluka, M., \& Bjelica, D. (2017). Stature and Its Estimation Utilizing Arm Span Measurements in Male Adolescents from Herzeg-Bosnia Entity in Bosnia and Herzegovina. Montenegrin Journal of Sports Science and Medicine, 6(1), 37-44.

Grasgruber, P., Cacek, J., Kalina, T., \& Seberaet, M. (2014). The role of nutrition and genetics as key determinants of the positive height trend. Economics \& Human Biology, 15, 81-100. doi: 10.1016/j.ehb.2014.07.002

Grgantov, Z., Padulo, J., Milić, M., Ardigò, L.P., Erceg, M., \& Cular, D. (2017). Intra-Positional and InterPositional Differences in Somatotype Components and Proportions of Particular Somatotype Categories in Youth Volleyball Players. Annals of Applied Sport Science, 5(2), 37-49. doi: 10.18869/acadpub.aassjournal.5.2.37

Hatton, T.J., \& Bray, B.E. (2010). Long run trends in the heights of European men, 19th-20th centuries. Economics and human biology, 8(3), 405-413. doi: 10.1016/j.ehb.2010.03.001

Herpin, N. (2003). La taille des hommes: son incidence sur la vie en couple et la carrière professionnelle. Economie et Statistique, 361(1), 71-90.

Iseri, A., \& Arslan, N. (2009). Obesity in adults in Turkey: age and regional effects. European Journal of Public Health, 19(1), 91-94. doi: 10.1093/eurpub/ckn107

Juresa, V., Musil, V., \& Tiljak, M.K. (2012). Growth charts for Croatian school children and secular trends in past twenty years. Collegium Antropologicum, 36(1), 47-57.

KFOR_Structur.2006 [PNG] (2006). Retrieved from https://upload.wikimedia.org/wikipedia/commons/c/ ce/KFOR_Structur.2006.PNG

Kułaga, Z., Litwin, M., Tkaczyk, M., Palczewska, I., Zajączkowska, M., Zwolińska, D., Krynicki, T., Wasilewska, A., Moczulska, A., Morawiec-Knysak, A., Barwicka, K., Grajda, A., Gurzkowska, B., Napieralska, E., \& Pan, H. (2011). Polish 2010 growth references for school-aged children and adolescents. European Journal of Pediatrics, 170(5), 599-609. doi: 10.1007/s00431-010-1329-x

Marfell-Jones, M., Olds, T., Stew, A.D., \& Carter, J.E.L. (2006). International standards for anthropometric assessment. Potchesfstroom: International Society for the Advancement of Kinanthropometry.

Masanovic, B., Milosevic, Z., \& Corluka, M. (2018). Comparative Study of Anthropometric Measurement and Body Composition between Junior Handball and Volleyball Players from Serbian National League. International Journal of Applied Exercise Physiology, 7(4), 1-6. doi: 10.30472/ijaep.v7i4.313

NCD Risk Factor Collaboration (2016). A century of trends in adult human height. eLife, 5:e13410. doi: 10.7554/eLife.13410.

Papadimitriou, A., Fytanidis, G., Douros, K., Papadimitriou, D.T., Nicolaidou, P., \& Fretzayas, A. (2008). Greek young men grow taller. Acta Paediatrica, 97(8), 1105-1107. doi: 10.1111/j.1651-2227.2008.00855.x

Pineau, J.C., Delamarche, P. \& Bozinovic, S. (2005). Average height of adolescents in the Dinaric Alps (in French). Comptes Rendus Biologies, 328(9), 841-846. doi: 10.1016/j.crvi.2005.07.004

Popovic, S. (2017). Local Geographical Differences in Adult Body Height in Montenegro. Montenegrin Journal of Sports Science and Medicine, 6(1), 81-87.

Popovic, S. (2018). Arm-span measurement as an alternative estimation of true height in Montenegrin young adults of both sexes: A national survey. Anthropological Notebooks, 24(1), 53-67.

Popovic, S., Arifi, F., \& Bjelica, D. (2017). Standing Height and its Estimation Utilizing Foot Length Measurements in Kosovan Adults: National Survey. International Journal of Applied Exercise Physiology, 6(2), 1-7. doi: 10.22631/ijaep.v6i2.150

Popovic, S., Bjelica, D., Georgijev, G., Krivokapic, D., \& Milasinovic, R. (2016). Body Height and its Estimation Utilizing Arm Span Measurements in Macedonian Adults. The Anthropologist, 24(3), 737-745. doi: 10.1080/09720073.2016.11892070

Popovic, S., Bjelica, D., Molnar, S., Jaksic, D., \& Akpinar, S. (2013). Body Height and Its Estimation Utilizing Arm Span Measurements in Serbian Adults. International Journal of Morphology, 31(1), 271-279. doi: 10.4067/S0717-95022013000100043

Popovic, S., Bjelica, D., Tanase, G.D., \& Milasinovic, R. (2015). Body Height and Its Estimation Utilizing Arm Span Measurements in Bosnian and Herzegovinian Adults. Montenegrin Journal of Sports Science and Medicine, 4(1), 29-36.

Quanjer, P.H., Capderou, A., Mazocioglu, M.M., Aggarwal, A., Popovic, S., Datta Banik, S., Tayie, F.A.K., Golshan, M., Ip, M.S.M., Zelter, M. (2014). All-age relationship between arm span and height in different ethnic groups. European Respiratory Journal, 44(4), 905-912. doi: 10.1183/09031936.00054014

Starc, G., \& Strel, J. (2011). Is there a rationale for establishing Slovenian body mass index references of school-aged children and adolescents? Anthropological Notebooks, 17(3), 89-100.

Stoop, R., Hohenauer, E., Rucker, M.L.A., Clijsen, R. (2018). Anthropometric Properties versus Physical Performance in Rugby ::union:: Forwards and Backs - A Systematic Review. Annals of Applied Sport Science, 6(2), 1-13. doi: 10.29252/aassjournal.6.2.1

Zoom into Dinaric Alps mountain range [PNG] (2017). Retrieved from https://www.motionelements.com/ stock-video-9696376-zoom-into-dinaric-alps-mountain-range-glowed-colored-physical-map 